\title{
Focus on therapy of hypnic headache
}

\author{
Carlo Lisotto $\cdot$ Paolo Rossi $\cdot$ Cristina Tassorelli $\cdot$ \\ Enrico Ferrante $\cdot$ Giuseppe Nappi
}

Received: 3 December 2009/Accepted: 18 May 2010/Published online: 29 June 2010

(C) Springer-Verlag 2010

\begin{abstract}
Hypnic headache ( $\mathrm{HH})$ is a primary headache disorder, which occurs exclusively during sleep and usually begins after 50 years of age. There are no controlled trials for the treatment of $\mathrm{HH}$. We reviewed all the available papers, including 119 cases published in literature up to date, reporting the efficacy of the medications used to treat $\mathrm{HH}$. Acute treatment is not recommended, since no drug proved to be clearly effective and also because the intensity and the duration of the attacks do not require the intake of a medication in most cases. As for prevention, a wide variety of medications were reported to be of benefit in $\mathrm{HH}$. The drugs that were found to be effective in at least five cases are: lithium, indomethacin, caffeine and flunarizine. Lithium was the most extensively studied compound and demonstrated to be an efficacious treatment in 32 cases. Unfortunately, despite its efficacy, significant adverse effects and poor tolerability are not rare, mainly in elderly
\end{abstract}

\section{Lisotto}

Headache Centre, Department of Neuroscience,

S. Vito al Tagliamento Hospital, Pordenone, Italy

P. Rossi

Headache Clinic INI Grottaferrata, Rome, Italy

C. Tassorelli $(\bowtie) \cdot$ G. Nappi

Headache Science Centre, IRCCS "Neurological Institute

C. Mondino" Foundation, University Centre for Headache and Adaptive Disorders (UCADH), University of Pavia,

Pavia, Italy

e-mail: cristina.tassorelli@mondino.it

E. Ferrante

Department of Neuroscience,

Niguarda Ca' Granda Hospital, Milan, Italy

G. Nappi

Chair of Neurology, University "La Sapienza”, Rome, Italy patients. Many patients reported a good response to indomethacin, but some could not tolerate it. Caffeine and melatonin treatments did not yield robust evidence to recommend their use as single preventive agents. Nevertheless, their association with lithium or indomethacin seems to produce an additional therapeutic efficacy. A course of lithium should be tried first, followed 3-4 months later by tapering. If headache recurs during tapering, a longer duration of therapy may be needed. If lithium treatment does not provide a significant response, indomethacin can be commenced as second-line approach. If these treatments prove to be ineffective or poorly tolerated, other agents, such as caffeine and melatonin, can be administered.

Keywords Hypnic headache · Therapy · Lithium · Indomethacin · Caffeine $\cdot$ Melatonin

\section{Background}

Hypnic headache $(\mathrm{HH})$ is a primary headache disorder, which occurs exclusively during sleep and usually begins after 50 years of age. Raskin first described the disorder in 1988 [1]; more than 100 cases have been subsequently reported. In the largest case series, $\mathrm{HH}$ was diagnosed in $0.07-0.1 \%$ of all headache patients assessed annually at a specialty clinic, reflecting the relative rarity of this condition [2]. HH usually begins late in life with a mean age at onset of $62 \pm 11$ years, with a range of 36-84 years. The mean duration of disease before diagnosis is $5 \pm 7$ years (range 0.1-35 years), suggesting that this condition is poorly recognized and perhaps underdiagnosed [2]. Three cases of probable $\mathrm{HH}$ in childhood and adolescence have been reported [3-5], although the occurrence at this age does not meet International Headache Society (IHS) 
Table 1 ICHD-II criteria for hypnic headache

Description: attacks of dull headache that always awaken the patient from sleep

Diagnostic criteria
A. Dull headache fulfilling criteria B-D
B. Develops only during sleep, and awakens patient
C. At least two of the following characteristics
1. Occurs $>15$ times per month
2. Lasts $\geq 15$ min after waking
3. First occurs after age of 50 years
D. No autonomic symptoms and no more than one of nausea, photophobia or phonophobia
E. Not attributed to another disorder

criteria. The condition is more prevalent in women $(65 \%)$ than in men; in a personal large case series, we found a greater majority of females, accounting for $87.9 \%$ [6]. No case with a family history of $\mathrm{HH}$ has been reported so far. Table 1 lists the International Classification of Headache Disorders Classification, 2nd edition (ICHD-II) criteria for $\mathrm{HH}$, that was included into group 4 (code 4.5), in the subheading of "Other primary headaches" [7].

Intracranial disorders must be excluded. Distinction from one of the trigeminal cephalalgias, in particular cluster headache, is necessary for effective management. The pain of $\mathrm{HH}$ is usually mild to moderate, but severe pain is reported by approximately $20 \%$ of patients. HHs occur in most cases at a consistent time each night, usually between 1:00 and 3:00 a.m., and may on rare instances occur during a daytime nap [2]. Pain is mainly bilateral, being unilateral in one-third of cases. It is usually localized anteriorly; on occasion it involves the occiput or radiates into the neck. The attacks usually last from 15 to $180 \mathrm{~min}$, even if longer durations have been described. The frequency of attacks is usually high. More than 4 attacks per week occur in $70 \%$ of the cases and about half of patients have daily attacks [2]. Associated autonomic symptoms accompany the pain in approximately $8 \%$ of sufferers, and nausea, photophobia and phonophobia may rarely be present. The natural history of $\mathrm{HH}$ is not well known. It is assumed that it tends to be chronic unremitting, but only a few patients have been observed for at least 2 years. Some authors have classified $\mathrm{HH}$ into two different forms, chronic and episodic form. The episodic form is further subdivided into two types, episodic with no recurrence, and relapsing and remitting variety. Episodic form without recurrence may show spontaneous resolution or sustained remission even after withdrawal of the effective drug [5, 8, 9]. In view of previously published data, we proposed that $\mathrm{HH}$ be divided in two subtypes, chronic and episodic. We suggested that episodes of this disorder with remission periods of $\geq 1$ month should be denoted by the term "episodic HH" and for those patients who have not experienced a remission over a period of at least 1 year, the disorder should be called "chronic HH" [8]. Some symptomatic cases have also been described, in which HH was linked to the onset of an intracranial lesion or disappeared after its removal. These cases were found to be secondary to a posterior fossa meningioma [10], a growth hormonesecreting pituitary tumour [11], and a nonfunctioning pituitary macroadenoma [12], respectively. Other cases of symptomatic HH related to obstructive sleep apnoea syndrome [13], ischaemic stroke in the midrostral upper pons [14], nocturnal arterial hypertension [15] and medication (ergotamine) overuse [16]. The exact pathophysiological mechanisms of $\mathrm{HH}$ have not yet been elucidated. It has been postulated that HH may be the result of a chronobiological disorder, serotonin, and melatonin dysregulation or a disturbance of rapid eye movement (REM) sleep. In most of the patients with $\mathrm{HH}$ who had polysomnographic studies, attacks were associated with REM sleep [2, 13, 1722]; however, non-REM related HHs have also been reported [23-26]. In a recent paper reporting the results of polysomnography in 7 subjects whose $\mathrm{HH}$ attacks were recorded during the sleep studies, 3 patients had their headache attacks exclusively during non-REM sleep, 2 patients in REM sleep and the other 2 patients having both [9]. Furthermore, HH might be a chronobiological disturbance [27], because many patients experience the headache attack always at the same time in the night ("alarm-clock headache"). The most important brain structure for the endogenous circadian rhythm is the suprachiasmatic nuclei (SCN). The SCN have afferent and efferent projections with the periaqueductal grey and aminergic nuclei, which are the most important brainstem structures for pain modulation. With advanced age, the function of the hypothalamic-pineal axis, and in particular of the $\mathrm{SCN}$, is diminished, and melatonin secretion is impaired or absent after the age of 60 years [2, 28-30]. The variety of drugs reported to be effective in $\mathrm{HH}$ (see below) also underscores the possibility that the pathophysiology might be heterogeneous. It is probable, given the differences in medication response and in polysomnographic studies, that more than one pathophysiological mechanism is responsible for $\mathrm{HH}$. Further investigations using sleep studies and functional neuroimaging are necessary to better understand this syndrome.

\section{Treatment}

In the following paragraphs, we summarize the information collected from a systematic analysis of the international literature on the treatment of $\mathrm{HH}$. We conducted a baseline literature search covering the period 1980-2009, 
employing available electronic databases (National Library of Medicine, National Institute of Health, Embase) with the following medical search terms: hypnic headache, alarmclock headache, nocturnal headache. Whenever available, chapters of book were also consulted and considered.

No controlled trials for the treatment of $\mathrm{HH}$ were found. Acute medications in the attack were tested only in a few patients. Notably, subcutaneous sumatriptan and oxygen inhalation, the treatments of first choice for cluster headache attacks, were not effective. Acetylsalicylic acid, caffeine and acetaminophen demonstrated, on average, only a mild efficacy for the acute relief of HH attacks. From the standpoint of preventive medications reported, lithium was used most frequently and also showed the best average efficacy. Lithium was the first treatment reported to be effective for $\mathrm{HH}$ [1]; this drug interacts with the painmodulating system possibly involved in this disorder and seems to increase indirectly nocturnal production of melatonin. Moreover, lithium may exert an enhancing effect on cerebral serotonin functions. Lithium carbonate can be initiated at $300 \mathrm{mg}$ at night and increased to $600 \mathrm{mg}$ after 1 or 2 weeks if necessary [1,9]. A good response was also noted with lower doses, even $150 \mathrm{mg}$ at bedtime [8]. Out of the patients treated with lithium, this drug was discontinued in 5 cases [1, 31-33] despite its efficacy, due to significant adverse effects. Poor tolerability to lithium is not rare, mainly in elderly patients. Renal and thyroid function should be assessed before initiating therapy, and periodically during treatment. Serum lithium concentrations should be monitored as well to avoid toxicity. Side effects include tremor, diarrhoea, increased thirst and polyuria. Recently, a transient HH was described in a patient with bipolar disorder after the withdrawal of long-term lithium treatment [34]. Many other agents that have been reported to effectively treat $\mathrm{HH}$ include bedtime doses of caffeine
(40-60 mg tablet, or as a cup of coffee), indomethacin, flunarizine, tricyclic antidepressants, verapamil, prednisone, topiramate, gabapentin, melatonin, benzodiazepines, pregabalin and acetazolamide. Curiously, of the patients treated with caffeine before bedtime, a disrupted sleep pattern was reported only in a few cases [27, 35]. The efficacy of indomethacin is of special interest because this drug is also effective in paroxysmal hemicrania and hemicrania continua [36]. It has been suggested that indomethacin may be helpful in those patients whose $\mathrm{HH}$ attacks are unilateral [31]. It was shown to be effective in extremely variable doses, ranging from $25 \mathrm{mg}$ to $150 \mathrm{mg} /$ day. Some patients who responded to indomethacin before bedtime developed daytime headaches, which resolved after indomethacin was discontinued. This phenomenon was termed as "the paradox of indomethacin", whose most prominent side effect and reason for discontinuation (headache) is the very symptom for which it provides a remarkable therapeutic efficacy [31]. Other patients reported a good response to indomethacin, but could not tolerate it $[21,37]$. Interestingly, the efficacy of topiramate, at the dose of $25 \mathrm{mg}$ at bedtime and $100 \mathrm{mg} / \mathrm{day}$ was recently reported in two cases [33, 38]. A list of all drugs, both acute and prophylactic, that provided some benefit and their efficacy, as reported by the respective authors, is presented in Tables 2 and 3, respectively. In a personal large case series, including 33 patients, that was recently published as an abstract [6], we found that the most effective treatments were caffeine ( 7 cases), indomethacin (4 cases), melatonin (4 cases), lithium at low doses + caffeine ( 3 cases), lithium ( 1 case) and verapamil ( 1 case). The remaining 13 cases reported no benefit, refused the treatment or did not need any medication, since they were pain-free after an episodic period. Based on the literature review and our study results, we suggest a
Table 2 Different acute drug treatments in the published case reports on hypnic headache

\begin{tabular}{llllll}
\hline Drugs & References & No. cases & \multicolumn{2}{l}{ Efficacy } & \\
\cline { 3 - 5 } & & & Good & Moderate & None \\
\hline Acetylsalicylic acid & {$[18,39]$} & 2 & 1 & 1 & \\
Acetylsalicylic acid + caffeine & {$[27]$} & 1 & 1 & & \\
Caffeine & {$[35,41]$} & 3 & 1 & 2 & \\
Acetaminophen & {$[4,19,33,40]$} & 4 & 1 & 1 & 2 \\
Sumatriptan 50 mg + caffeine & {$[27]$} & 1 & 1 & & 3 \\
Nimesulide & {$[19,32,33,42]$} & 4 & 1 & & 1 \\
Ibuprofen & {$[5,32]$} & 2 & 1 & & 3 \\
Triptans others than sumatriptan & {$[5,32,33,39]$} & 4 & & 1 & \\
Ergotamine & {$[40]$} & 1 & & 1 & 4 \\
Sumatriptan 50-100 mg & {$[5,19,31,33]$} & 4 & & & 3 \\
Oxygen inhalation & {$[5,13,18]$} & 3 & & & \\
Indomethacin & {$[19,33]$} & 2 & & & \\
Sumatriptan 6 mg s.c. & {$[18]$} & 1 & & & \\
\hline
\end{tabular}


Table 3 Different prophylactic drug treatments in the published case reports on hypnic headache

\begin{tabular}{|c|c|c|c|c|c|}
\hline \multirow[t]{2}{*}{ Drugs } & \multirow[t]{2}{*}{ References } & \multirow[t]{2}{*}{ No. cases } & \multicolumn{3}{|c|}{ Efficacy } \\
\hline & & & Good & Moderate & None \\
\hline Lithium & {$[1,8,9,13,17,19,20,23,32,33,36,38,40,41,43-48]$} & 47 & 32 & 10 & 5 \\
\hline Lithium + caffeine & {$[8,35]$} & 4 & 4 & & \\
\hline Lithium + dothiepin + alprazolam & {$[40]$} & 1 & 1 & & \\
\hline Lithium + venlafaxine & [49] & 1 & 1 & & \\
\hline Lithium + amitriptyline & [41] & 1 & & 1 & \\
\hline Indomethacin & {$[5,21-23,27,31,32,35,37,44,46,49-52]$} & 22 & 10 & 3 & 9 \\
\hline Indomethacin + caffeine & {$[31,41]$} & 2 & 1 & 1 & \\
\hline Caffeine & {$[8,18,27,31,32,39,41,50-52]$} & 15 & 5 & 4 & 6 \\
\hline Caffeine + melatonin & {$[32]$} & 2 & & 2 & \\
\hline Flunarizine & {$[9,17-19,32,33,38,41,53,54]$} & 13 & 5 & 1 & 7 \\
\hline Flunarizine + melatonin & {$[54]$} & 1 & 1 & & \\
\hline Tricyclic antidepressants & {$[5,18,19,23,25,26,31,33,39,41]$} & 14 & 2 & 2 & 10 \\
\hline Prednisone & {$[8,13,27,32,38,42]$} & 7 & 2 & 1 & 4 \\
\hline Verapamil & {$[18,19,31,32]$} & 5 & 2 & & 3 \\
\hline Verapamil + amitryptiline & [18] & 1 & 1 & & \\
\hline Topiramate & {$[33,38]$} & 2 & 2 & & \\
\hline Gabapentin & {$[23,32,52]$} & 3 & 1 & 1 & 1 \\
\hline Melatonin & {$[31,52]$} & 4 & 1 & & 3 \\
\hline Benzodiazepines & {$[13,19]$} & 2 & 1 & & 1 \\
\hline Atenolol $25 \mathrm{mg}$ & [27] & 1 & 1 & & \\
\hline Pregabalin & {$[52]$} & 1 & 1 & & \\
\hline Acetazolamide & {$[37]$} & 1 & 1 & & \\
\hline Botulinum toxin type A & [39] & 1 & 1 & & \\
\hline Cinnarizine & {$[32]$} & 1 & 1 & & \\
\hline Ergotamine + phenobarbital & {$[27]$} & 1 & 1 & & \\
\hline Acetylsalicylic acid + caffeine & {$[27]$} & 1 & 1 & & \\
\hline Eszopiclone & {$[55]$} & 1 & 1 & & \\
\hline Clorazepate + venlafaxine + valproate & {$[34]$} & 1 & 1 & & \\
\hline Oxetorone & {$[48]$} & 8 & & 8 & \\
\hline Atenolol $50 \mathrm{mg}$ & {$[32,41]$} & 3 & & 2 & 1 \\
\hline Propranolol & {$[5,13,19,33]$} & 7 & & & 7 \\
\hline Antidepressants others than tricyclics & {$[5,13,23,39,49]$} & 6 & & & 6 \\
\hline Pizotifen & {$[19,23,32,33,38]$} & 4 & & & 4 \\
\hline Methysergide & {$[13,23]$} & 3 & & & 3 \\
\hline Valproate & {$[5,19,33]$} & 3 & & & 3 \\
\hline Ergotamine & {$[31]$} & 1 & & & 1 \\
\hline Acetylsalicylic acid & [31] & 1 & & & 1 \\
\hline
\end{tabular}

practical approach to the management of $\mathrm{HH}$, which is shown in Fig. 1. Although some patients may specifically ask for an acute treatment, this is not recommended, since no drug showed to be clearly effective; furthermore, the mild-to-moderate intensity and the short duration of the attacks do not require the intake of acute medications in most cases. The attacks subside spontaneously in a relatively short time, almost never exceeding the duration of $2-$ $3 \mathrm{~h}$. Moreover, the intensity is mild to moderate in the majority of cases. The patients themselves are more concerned with the prevention of the headaches, rather than with the treatment of the single attacks. As for prophylaxis, a course of 300-600 mg lithium should be tried first, on some instances in association with caffeine and/or melatonin, followed, 3-4 months later, by tapering. If headache recurs during tapering, a longer duration of therapy may be needed. The treatment with caffeine and in particular with melatonin alone did not yield robust evidence to 


\section{Suggested flowchart for the treatment of Hypnic Headache}

First line recommended treatment

\section{$\downarrow$}

Litihum 300-600 mg at bedtime

(possible association with caffeine and/or melatonin)

Second line recommended treatment

Indomethacin $25-75 \mathrm{mg}$ and/or caffeine at bedtime

Third line recommended treatment

1

Other drugs (verapamil or flunarizine or topiramate) at bedtime, (possible association with caffeine and/or melatonin)

Fig. 1 Suggested approach to the management of $\mathrm{HH}$

recommend their use as single preventive agents. Their association with the recommended medications (i.e. lithium and indomethacin) seems to produce an additional overall therapeutic efficacy. Anyway, some patients responded completely to caffeine given alone at bedtime. If lithium treatment does not provide a significant response, as second line approach indomethacin can be commenced, at a dose ranging from 25 to $75 \mathrm{mg}$ at bedtime; based on the above remarks, caffeine can also be tried, alone or in combination with indomethacin. If these treatments prove to be ineffective, other medications, such as verapamil, flunarizine or topiramate, can be administered. These drugs are also recommended when lithium and indomethacin are contraindicated or are related to significant side effects.

Conflict of interest None.

\section{References}

1. Raskin NH (1988) The hypnic headache syndrome. Headache 28:534-536

2. Evers S, Goadsby PJ (2003) Hypnic headache: clinical features, pathophysiology, and treatment. Neurology 60:905-909

3. Grosberg BM, Lipton RB, Solomon S, Ballaban-Gil K (2005) Hypnic headache in childhood? A case report. Cephalalgia 25:68-70

4. Scagni P, Pagliero R (2008) Hypnic headache in childhood: a new case report. J Paediatr Child Health 44:83-84

5. Prakash S, Dahbi AS (2008) Relapsing remitting hypnic headache responsive to indomethacin in an adolescent: a case report. J Headache Pain 9:393-395

6. Lisotto C, Mainardi F, Maggioni F, Zanchin G (2009) Migraine and hypnic headache: comorbidity or possible evolution over time? J Headache Pain 10(Suppl):S33-S34

7. Headache Classification Subcommittee of the International Headache Society (2004) The International Classification of Headache Disorders, 2nd edn. Cephalalgia 24 (Suppl 1):1-160
8. Lisotto C, Mainardi F, Maggioni F, Zanchin G (2004) Episodic hypnic headache? Cephalalgia 24:681-685

9. Liang J-F, Fuh J-L, Yu C-Y, Hsu C-Y, Wang S-J (2008) Clinical features, polysomnography and outcome in patients with hypnic headache. Cephalalgia 28:209-215

10. Peatfield RC, Mendoza ND (2003) Posterior fossa meningioma presenting as hypnic headache. Headache 43:1007-1008

11. Valentinis L, Tuniz F, Mucchiut M, Vindigni M, Skrap M, Bergonzi P, Zanchin G (2009) Hypnic headache secondary to a growth hormone-secreting pituitary tumour. Cephalalgia 29:82-84

12. Garza I, Oas KH (2009) Symptomatic hypnic headache secondary to a nonfunctioning pituitary macroadenoma. Headache 49:470472

13. Dodick DW (2000) Polysomnography in hypnic headache syndrome. Headache 40:748-752

14. Moon H-S, Chung C-S, Hong S-B, Kim Y-B, Chung P-W (2006) A case of symptomatic hypnic headache syndrome. Cephalalgia 26:81-83

15. Gil-Gouveia R, Goadsby PJ (2007) Secondary "hypnic headache". J Neurol 254:646-654

16. Baykan B, Ertaş M (2008) Hypnic headache associated with medication overuse: case report. Agri 20:40-43

17. Morales-Asín F, Mauri JA, Iñiguez C, Espada F, Mostacero E (1998) The hypnic headache syndrome: report of three new cases. Cephalalgia 18:157-158

18. Evers S, Rahmann A, Schwaag S, Lüdemann P, Husstedt IW (2003) Hypnic headache-the first German cases including polysomnography. Cephalalgia 23:20-23

19. Pinessi L, Rainero I, Cicolin A, Zibetti M, Gentile S, Mutani R (2003) Hypnic headache syndrome: association of the attacks with REM sleep. Cephalalgia 23:150-154

20. Patsouros N, Laloux P, Ossemann M (2004) Hypnic headache: a case report with polysomnography. Acta Neurol Belg 104:37-40

21. Peters N, Lorenzl S, Fischereder J, Bötzel K, Straube A (2006) Hypnic headache: a case presentation including polysomnography. Cephalalgia 26:84-86

22. Seidel S, Zeitlhofer J, Wöber C (2008) First Austrian case of hypnic headache: serial polysomnography and blood pressure monitoring in treatment with indomethacin. Cephalalgia 28:1086-1090

23. Molina Arjona JA, Jiménez-Jiménez FJ, Vela-Bueno A, TallónBarranco A (2000) Hypnic headache associated with stage 3 slow wave sleep. Headache 40:753-754

24. Manni R, Sances G, Terzaghi M, Ghiotto N, Nappi G (2004) Hypnic headache: PSG evidence of both REM- and NREMrelated attacks. Neurology 62:1411-1413

25. Capuano A, Vollono C, Rubino M, Mei D, Calì C, De Angelis A, Di Trapani G, Servidei S, Della Marca G (2005) Hypnic headache: actigraphic and polysomnographic study of a case. Cephalalgia 25:466-469

26. Dolso P, Merlino G, Fratticci L, Canesin R, Valiante G, Coccolo D, Gigli GL (2007) Non-REM hypnic headache: a circadian disorder? A clinical and polysomnographic study. Cephalalgia 27:83-86

27. Dodick DW, Mosek AC, Campbell IK (1998) The hypnic ("alarm clock") headache syndrome. Cephalalgia 18:152-156

28. Dodick DW, Eross EJ, Parish JM (2003) Clinical, anatomical, and physiologic relationship between sleep and headache. Headache 43:282-292

29. Cohen AS, Kaube H (2004) Rare nocturnal headaches. Curr Opin Neurol 17:295-299

30. Pascual J (2009) Other primary headaches. Neurol Clin 27:557571

31. Dodick DW, Jones JM, Capobianco DJ (2000) Hypnic headache: another indomethacin-responsive headache syndrome? Headache 40:830-835 
32. Ghiotto N, Sances G, Di Lorenzo G, Trucco M, Loi M, Sandrini G, Nappi G (2002) Report of eight new cases of hypnic headache and a mini-review of the literature. Funct Neurol 17:211-219

33. Guido M, Specchio LM (2006) Successful treatment of hypnic headache with topiramate: a case report. Headache 46:1205-1206

34. Karlovasitou A, Avdelidi E, Andriopoulou G, Baloyannis S (2009) Transient hypnic headache syndrome in a patient with bipolar disorder after the withdrawal of long-term lithium treatment: a case report. Cephalalgia 29:484-486

35. Zanchin G, Lisotto C, Maggioni F (2000) The hypnic headache syndrome. The first description of an Italian case. J Headache Pain 1:60

36. Goadsby PJ, Lipton RB (1997) A review of paroxysmal hemicranias, SUNCT syndrome and other short-lasting headache with autonomic feature including new cases. Brain 120:193-209

37. Sibon I, Ghorayeb I, Henry P (2003) Successful treatment of hypnic headache with acetazolamide. Neurology 61:1157-1158

38. Autunno M, Messina C, Blandino A, Rodolico C (2008) Hypnic headache responsive to low-dose topiramate: a case report. Headache 48:292-294

39. Marziniak M, Voss J, Evers S (2007) Hypnic headache successfully treated with botulinum toxin type A. Cephalalgia 27:1082-1084

40. Martins IP, Gouveia RG (2001) Hypnic headache and travel across time zones: a case report. Cephalalgia 21:928-931

41. Pinto CAR, Fragoso YD, de Souza Carvalho D, Gabbai AA (2002) Hypnic headache syndrome: clinical aspects of eight patients in Brazil. Cephalalgia 22:824-827

42. Relja G, Zorzon M, Locatelli L, Carraro N, Antonello RM, Cazzato $\mathrm{G}$ (2002) Hypnic headache: rapid and long-lasting response to prednisone in two new cases. Cephalalgia 22:157-159

43. Newman LC, Lipton RB, Solomon S (1990) The hypnic headache syndrome: a benign headache disorder of the elderly. Neurology 40:1904-1905
44. Ivañez V, Soler R, Barreiro P (1998) Hypnic headache syndrome: a case with good response to indomethacin. Cephalalgia 18:225226

45. Pérez-Martínez DA, Berbel-García A, Puente-Muñoz AI, SáizDíaz RA, de Toledo-Heras M, Porta-Etessam J, Martínez-Salio A (1999) Hypnic headache: a new case. Rev Neurol 28:883-884

46. Vieira-Dias M, Esperança P (2001) Hypnic headache: report of two cases. Headache 41:726-727

47. Vieira Dias M, Esperança P (2002) Hypnic headache: a report of four cases. Rev Neurol 34:950-951

48. Donnet A, Lantéri-Minet M (2009) A consecutive series of 22 cases of hypnic headache in France. Cephalalgia 29:928-934

49. Gould JD, Silberstein SD (1997) Unilateral hypnic headache: a case study. Neurology 49:1749-1751

50. Centonze V, D’Amico D, Usai S, Causarano V, Bassi A, Bussone G (2001) First Italian case of hypnic headache, with literature review and discussion of nosology. Cephalalgia 21:71-74

51. Buzzi MG, Cologno D, Formisano R, Caltagirone C (2005) Hypnic headache responsive to indomethacin: second Italian case. Funct Neurol 20:85-87

52. Ulrich K, Gunreben B, Lang E, Sittl R, Grießinger N (2006) Pregabalin in the therapy of hypnic headache. Cephalalgia 26:1031-1032

53. Klimek A, Sklodowski P (1999) Night headache: report of 2 cases. Neurol Neurochir Pol 33(Suppl 5):49-54

54. Domitrz I (2005) Hypnic headache as a primary short-lasting night headache: a report of two cases. Neurol Neurochir Pol 39:77-79

55. Garza I, Swanson J (2007) Successful preventive therapy in hypnic headache using hypnotics: a case report. Cephalalgia 27:1080-1081 